\title{
PENDUGAAN BAWAH PERMUKAAN FORMASI WALANNAE MENGGUNAKAN METODE RESISTIVITAS
}

\author{
Debby Rahayu, Agung Hasan, Nurita Dwi Puspitasari, Muhammad Fawzy Ismullah \\ Massinai*
}

Departemen Geofisika FMIPA Universitas Hasanuddin, Makassar

*Penulis koresponden. fawzy@ sci.unhas.ac.id

\begin{abstract}
Abstrak
Penyelidikan mengenai bawah permukaan semakin digalakkan demi menjamin pembangunan yang berkelanjutan di permukaan tanah. Pembangunan intensif dilaksanakan di Desa Bira, Kecamatan Bontobahari, Kabupaten Bulukumba, yang merupakan salah satu daerah andalan pariwisata di Sulawesi Selatan. Oleh karena itu, studi identifikasi kondisi bawah permukaan semestinya sedini mungkin dilaksanakan. Penyelidikan ini bertujuan untuk menentukan jenis dan sebaran lapisan bawah permukaan menggunakan metode geolistrik resistivitas secara sederhana sebagai data awal penyelidikan berikutnya yang lebih terperinci. Metoda ini menggunakan prinsip aliran arus listrik yang mengalir di dalam tanah melalui batuan-batuan. Pada penelitian geolistrik resistivitas ini menggunakan konfigurasi Wenner Schlumberger. Pada penelitian ini terdapat sebuah lintasan pengukuran resistivitas mapping dengan jumlah elektroda sebanyak 30 dan spasi tiap elektroda $5 \mathrm{~m}$. Hasil yang didapatkan berupa penampang resistivitas yang memperlihatkan adanya 3 lapisan yaitu low resistivity $(<6,44 \Omega \mathrm{m})$, medium resistivity $(16,6-285 \Omega \mathrm{m})$ dan high resistivity $285-1892 \Omega \mathrm{m}$. Lapisan ini berturut turut diduga merupakan lapisan lempung-pasir yang memungkinkan mengandung air tanah/ Ground water, lapisan alluvium dan lapisan batugamping terumbu.
\end{abstract}

Kata Kunci: Bira; mapping; resistivitas; Wenner - Schlumberger.

\begin{abstract}
Investigations on subsurface are increasingly being promoted to ensure sustainable development at the surface level. Intensive development was carried out in Bira Village, Bontobahari Subdistrict, Bulukumba Regency, which is one of the mainstays of tourism in South Sulawesi. Therefore, studies on identification of subsurface conditions should be carried out as soon as possible. This investigation aims to determine the type and distribution of subsurface layers using a simple resistivity geoelectric method as preliminary data for further detailed investigations. This method uses the principle of electric current flowing in the subsurface through rocks. In this resistivity geoelectrical investigation using the Wenner-Schlumberger configuration. In this study, there is a resistivity mapping acuisition line with 30 electrodes and $5 \mathrm{~m}$ range each electrode. The results obtained in the form of a resistivity cross section showing the presence of 3 layers, namely low resistivity $(<6.44 \Omega \mathrm{m})$, medium resistivity (16.6 - 285 $\Omega \mathrm{m})$ and high resistivity $285-1892 \Omega \mathrm{m}$. This layer is thought to be a successive layer of sand-clay which allows containing ground water/ ground water, alluvium layer and reef limestone layer.
\end{abstract}

Keywords: Bira; mapping; resistivity; Wenner - Schlumberger. 


\section{Pendahuluan}

Penyelidikan mengenai bawah permukaan semakin digalakkan demi menjamin pembangunan yang berkelanjutan di permukaan tanah. Jenis batuan yang berada di bawah permukaan dapat diketahui berdasarkan resistivitas (tahanan jenis) suatu batuan dengan menggunakan metode geolistrik resistivitas (tahanan jenis) (Dewi dkk., 2015).

Desa Bira merupakan salah satu desa yang ada di Kec. Bontobahari Kabupaten Bulukumba, yang merupakan salah satu daerah andalan pariwisata di Sulawesi Selatan. Selain karena keindahan pantainya, para wisatawan juga dapat melihat langsung pembuatan perahu tradisional khas Sulawesi Selatan yakni Phinisi. Meningkatnya jumlah wisatawan harus diimbangi dengan kenyamanan akan kebutuhan para pengunjung, seperti pembangunan infrastruktur dan fasilitas lainnya yang dibangun di atas permukaan. Oleh karena itu, studi identifikasi kondisi bawah permukaan semestinya sedini mungkin dilaksanakan di daerah ini demi terjaminnya kelangsungan kehidupan manusia dan kenyamanan wisatawan. Maka dari itu sangat perlu dilakukan survei geolistrik untuk membantu perencanaan terpadu di daerah tersebut.

Penyelidikan ini bertujuan untuk menentukan jenis dan sebaran lapisan bawah permukaan daerah penelitian menggunakan metode geolistrik resistivitas secara sederhana sebagai data awal penyelidikan berikutnya yang lebih terperinci. Pengambilan data dilakukan secara primer menggunakan metode geolistrik resistivitas mapping Konfigurasi Wenner - Schlumberger. Pengolahan data menggunakan perangkat lunak X2IPI (Robain dan Bobachev, 2017) dan interpretasi untuk menentukan jenis dan sebaran lapisan bawah permukaan daerah penelitian.
Daerah penelitian terletak di Desa Bira Kec. Bontobahari Kab. Bulukumba. Secara geologi daerah ini terdiri dari terumbu PlioPleistosen, Terumbu Pleistosen dan bahkan karang modern yang termasuk anggota Kapur Selayar, Formasi Walanae (Imran dkk., 2017). Batuan terbuka di beberapa teras menunjukkan fluktuasi muka laut dan/ atau kegiatan tektonik selama proses pembentukannya. Wilayah studi mengalami pengangkatan, membentuk teras batugamping terumbu ditandai dengan adanya takik (Imran, 2000). Stratigrafi daerah Bira dan sekitarnya tersusun atas 1) batugamping foraminifera miosen awal, 2) terumbu karang Miosen Akhir hingga Pliosen, 3) Terumbu karang Pliosen dan 4) terumbu karang Pleistosen (Imran, 2000). Setiap unit ditandai dengan teras yang menunjukkan batuan tertua terekspos ke arah darat dengan ketinggian yang lebih tinggi, sedangkan termuda terekspos ke arah laut dengan ketinggian yang lebih rendah. Teras bawah telah dideskripsikan sebagai terumbu Pleistosen yang lebih rendah (Imran, 2000) dan di Pulau Selayar berumur Pleistosen awal atau 1,6 sampai 1,4 Ma (Bromfield, 2013).

Terdapat banyak metode geofisika dalam bidang eksplorasi, di antaranya menentukan anomali gravitasi, magnet, elastisitas, radioaktif. Metode geolistrik merupakan metode yang menggunakan arus listrik untuk mendeteksi bawah permukaan dengan mengukur beda potensial yang dihasilkan. Metode geolistrik dapat digunakan untuk mengukur potensial - potensial, arus dan medan medan elektromagnetik yang terjadi secara alami atau buatan di dalam bumi. Pengukuran bisa dilakukan dalam berbagai variasi sesuai dengan kebutuhan (Telford dkk., 1990).

Penggunaan metode geolistrik resistivitas dalam pendugaan bawah permukaan telah jamak dilakukan. Virman dkk. (2019) menggunakan Metode Geolistrik 1D konfigurasi Schlumberger dalam 
penyelidikan zona akuifer di Sentani Timur, Jayapura, Papua. Wahyuni dkk. (2018) meneliti potensi air tanah di daerah sepanjang pesisir Desa Bira Kec. Bontobahari Kab. Bulukumba menggunakan Metode Geolistrik 1D konfigurasi Schlumberger. Penelitian yang disebut terakhir menjadi acuan dalam penelitian ini.

\section{Metode Geolistrik Resistivitas}

Metode geolistrik resistivitas/ tahanan jenis (selanjutnya ditulis metode resistivitas) secara teori lebih baik digunakan dibandingkan dengan semua metode geolistrik yang lain, karena menggunakan metode aktif dengan mengalirkan arus listrik ke bawah permukaan. Namun, nilai maksimum beda potensial secara ideal jarang ditemukan karena keadaan bawah permukaan yang begitu kompleks. Kelemahan utamanya adalah memiliki sensitivitas yang tinggi dalam mengukur konduktivitas dekat permukaan atau biasa disebut memiliki noise sangat tinggi (Telford et al., 1990).

Metode resistivitas didasari pada asumsi bahwa bumi bersifat homogen isotropis. Berdasarkan hal tersebut, resistivitas yang terukur adalah resistivitas yang sebenarnya dan tidak tergantung pada jarak antar elektroda. Kenyataannya, bumi terdiri atas lapisan dengan resistivitasnya masing masing, sehingga potensial yang terukur dipengaruhi oleh lapisan - lapisan tersebut. Dengan demikian, resistivitas yang terukur bukan merupakan nilai resistivitas untuk satu lapisan saja. Dalam hal ini yang terukur adalah resistivitas semu (Febriana dkk., 2017).

Resistivitas semu dihitung berdasarkan persamaan (Reynolds, 1997; Telford et al., 1990).

$$
\rho=K \frac{\Delta V}{I}
$$

dengan $\rho \quad$ : resistivitas semu $(\Omega \mathrm{m})$

$\mathrm{K}$ : faktor geometri konfigurasi elektroda (m)

$\Delta \mathrm{V}$ : beda potensial $(\mathrm{V})$

I : arus yang diinjeksikan (A)

Data yang diukur merupakan data nilai beda potensial bawah permukaan. Berdasarkan data tersebut kemudian dilakukan perhitungan inversi sesuai Pers. (1) sehingga didapatkan variasi distribusi resistivitas dari suatu kesatuan pelapisan yang berkaitan dengan struktur geologi di bawah permukaan. Metode resistivitas dapat menghasilkan variasi distribusi resistivitas, baik ke arah horisontal maupun vertikal. Berdasarkan nilai tersebut, dapat diketahui pula jenis material pada lapisan tersebut (Febriana dkk., 2017).

Telah disinggung sebelumnya bahwa metode resistivitas dapat memberikan variasi distribusi resistivitas, baik ke arah horizontal maupun vertikal. Hal ini didasari dari teknik pengukuran yang digunakan. Metode sounding digunakan untuk mendapatkan variasi distribusi resistivitas lapisan bawah permukaan secara vertikal. Sedangkan secara horizontal menggunakan metode mapping (Febriana dkk., 2017).

Bumi tersusun atas lapisan - lapisan (layers) tanah yang memiliki nilai resistivitas yang berbeda beda. Nilai ini dapat diketahui dengan menghubungkan sumber arus dengan sebuah perangkat pengukur arus dan beda potensial. Perangkat tersebut dihubungkan dengan elektroda arus untuk mengukur sejumlah arus yang mengalir ke dalam tanah, dan dengan elektroda potensial dengan jarak tertentu untuk mengukur perbedaan potensial (Utama, 2005).

Survei resistivitas menggunakan dua pasang elektroda, masing - masing untuk arus dan potensial (Syamsuddin dan Lantu, 2009). Susunan elektroda ini disebut konfigurasi elektroda (Gambar 1). 
a).

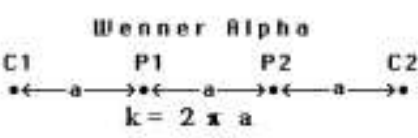

c).

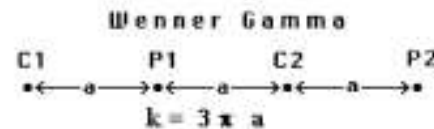

c).

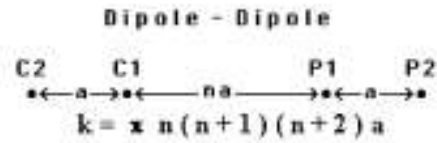

9].

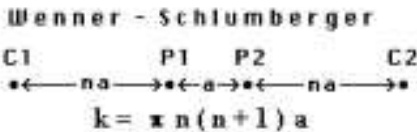

$\mathrm{k}=\mathrm{Geometric}$ Factor b).

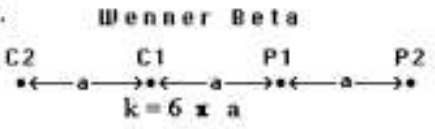

d).

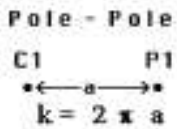

1).

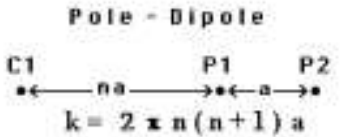

h).

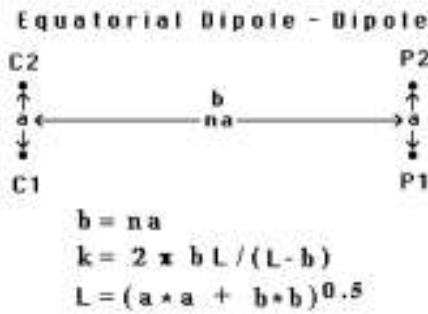

Gambar 1. Susunan konfigurasi elektroda dan faktor geometrinya (Loke, 2001).

Salah satu konfigurasi elektroda yang sering digunakan adalah konfigurasi Wenner - Schlumberger (Gambar 1(g)). Keunggulan dari konfigurasi Wenner Schlumberger dibanding dengan konfigurasi lainnya terletak pada elektroda arus dan potensial yang selalu berpindah posisi. Hal ini menjadikan konfigurasi ini sensitif terhadap adanya ketidakhomogenan yang bersifat lokal, seperti lensa dan gawir di bawah permukaan. Sifat sensitifitas ini muncul dari beda potensial yang terukur cukup besar sebab jarak antara elektoda potensial yang cukup besar. Keunggulan ini menjadikan konfigurasi Wenner - Schlumberger cukup sesuai untuk survey pemetaan batuan bawah permukaan dengan cakupan yang dalam (Sunarya dkk., 2017).

Nilai resistivitas batuan tergantung dari beberapa faktor, seperti derajat kekompakan, besarnya presentase kandungan fluida yang mengisi batuan, kandungan lempung, keterdapatan air tanah, jenis dan karakteristik fisik batuan, mineralogi batuan, dan sebagainya. Hal tersebut menyebabkan nilai dari beberapa jenis batuan biasanya overlap, seperti nilai resistivitas beberapa batuan pada Tabel 1 .
Tabel 1 Nilai resistivitas beberapa batuan (Telford et al., 1990; Reynolds, 1997).

\begin{tabular}{|c|c|}
\hline Material & $\begin{array}{c}\text { Resistivity } \\
(\Omega \mathrm{m})\end{array}$ \\
\hline Galena & $3 \times 10^{-5}-3 \times 10^{2}$ \\
\hline Hematit & $3.5 \times 10^{-3}-10^{7}$ \\
\hline Limonit & $10^{3}-10^{7}$ \\
\hline Kalsit & $1 \times 10^{12}-1 \times 10^{13}$ \\
\hline Kwarsa & $500-800000$ \\
\hline Garam Batu & $30-1 \times 10^{13}$ \\
\hline Granit & $200-10000$ \\
\hline Andesit & $1.7 \times 10^{2}-45 \times 10^{4}$ \\
\hline Basal & $200-100000$ \\
\hline Batugamping & $500-10000$ \\
\hline Batupasir & $200-8000$ \\
\hline Batusabak & $20-2000$ \\
\hline Pasir & $1-1000$ \\
\hline Lempung & $1-100$ \\
\hline Air Tanah & $0.5-300$ \\
\hline Air Laut & 0.2 \\
\hline Kerikil Kering & $600-10000$ \\
\hline Alluvium & $10-800$ \\
\hline Tanah (40\% lempung) & 8 \\
\hline Tanah (20\% lempung) & 33 \\
\hline Tanah Permukaan & $250-1700$ \\
\hline Pasir-Lempung & $30-215$ \\
\hline Laterit & $800-1500$ \\
\hline
\end{tabular}




\section{Metode Penelitian}

Penelitian ini dilakukan di Desa Bira Kec. Bontobahari Kab. Bulukumba Prov. Sulawesi Selatan. Titik pengambilan data secara geografis terletak pada koordinat $120^{\circ} 27^{\prime} 40^{\prime \prime}$ BT dan $05^{\circ} 35^{\prime} 47^{\prime \prime}$ LS seperti pada Gambar 2. Kegiatan pengolahan data dan analisis dilaksanakan di Laboratorium Geofisika Padat Dept. Geofisika FMIPA Universitas Hasanuddin.

Metode yang digunakan adalah metode geolistrik resistivitas mapping konfigurasi Wenner - Schlumberger. Data yang digunakan pada penelitian ini merupakan data primer yang diambil pada $4-7$ April
2019. Data resisitivitas yang diperoleh berasal dari sebuah lintasan yang berarah Barat Daya - Timur Laut, jumlah elektroda 30 buah dengan spasi 5 m.Data yang diperoleh berupa nilai koordinat, elevasi, arus, beda potensial. Perpindahan elektroda menyebabkan perubahan spasi yang menjadi masukan untuk perhitungan faktor geometri. Semua data tersebut diolah menggunakan Pers. (1) pada program pengolah data tabulasi sehingga nilai resistivitas semu didapatkan. Nilai ini menjadi masukan pada perangkat lunak X2IPI (Robain dan Bobachev, 2017) untuk pengolahan data sehingga didapatkan penampang variasi distribusi resistivitas.

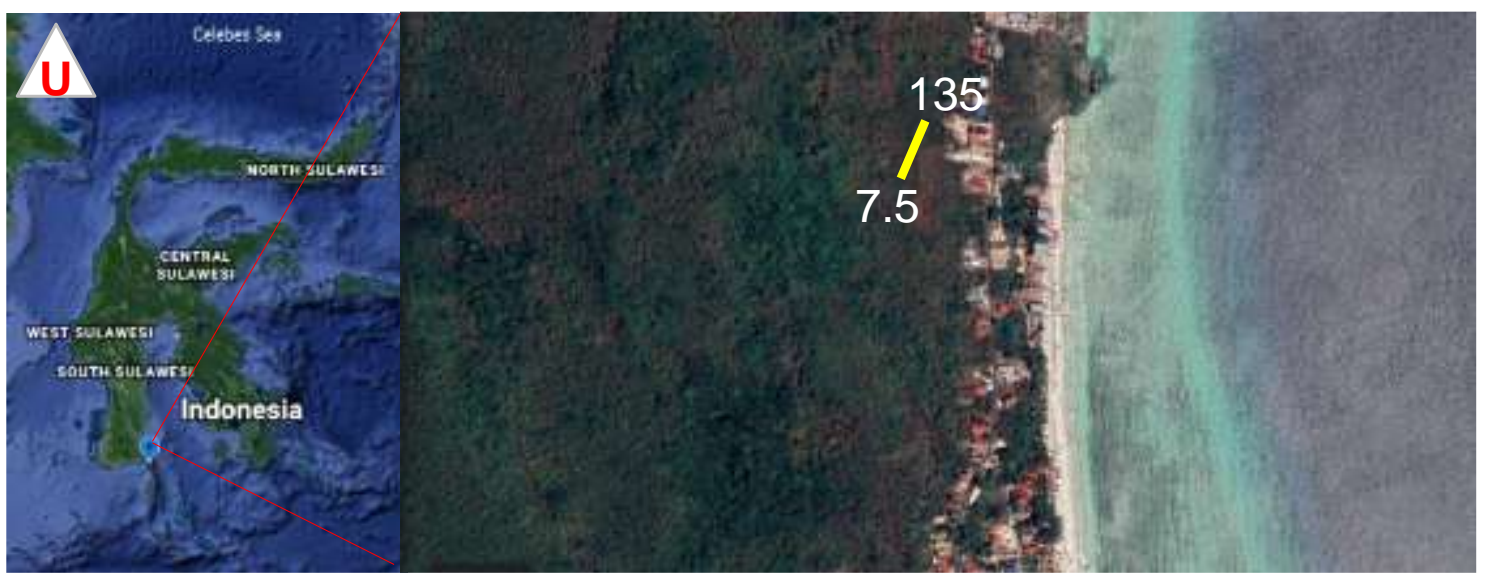

Gambar 2. Lokasi penelitian.

\section{Hasil dan Pembahasan}

Berikut adalah penampang resistivitas dari lintasan tersebut.

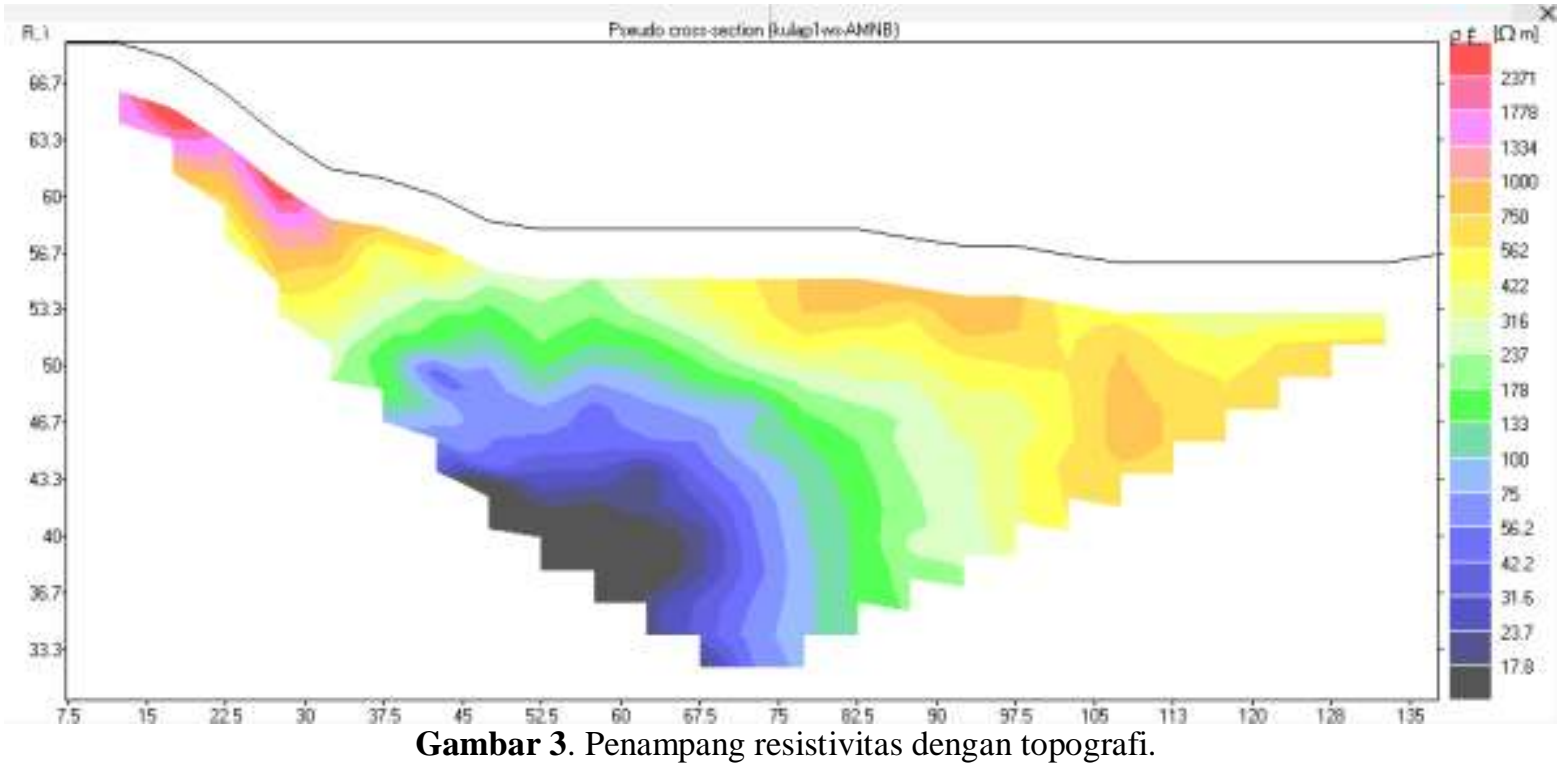


Penampang hasil pengolahan data konfigurasi Wenner - Schlumberger (Gbr. 3) setelah dilakukan 5 kali iterasi didapatkan RMS Error sebesar 21,794\% dan memiliki kedalaman 28,7 meter. Hasil inversi menampilkan 3 kategori nilai resistivitas yaitu low resistivity $2,50-16,6$ $\Omega \mathrm{m}$, medium resistivity $16,6-285 \Omega \mathrm{m}$, dan high resistivity $285-1892 \Omega \mathrm{m}$. Analisis nilai resistivitas didasari pada Tabel 1 , penampang tersebut terlihat untuk low resistivity $(<6,44 \Omega \mathrm{m})$ diduga merupakan lempung, pasir atau air tanah/ Ground water. Bagian ini ditunjukkan pada titik 50 - 90 meter dengan kedalaman $24-29$ meter.

Hal yang dapat mendukung hasil ini adalah terdapat sumur yang tidak pernah kering yang mengindikasikan keterdapatan Ground water. Menurut Wahyuni dkk. (2018) pada kedalaman tersebut terdapat retakan batuan yang memungkinkan terisi air akibat infiltrasi dari lapisan batuan di atasnya.

Lapisan medium resistivity 16,6 - $285 \Omega \mathrm{m}$ terletak di bawah lapisan low resistivity. Lapisan ini mencapai kedalaman hingga 35 meter. Lapisan ini diduga sebagai alluvium yang memungkinkan memiliki kandungan air. Lapisan high resistivity $285-1892 \Omega \mathrm{m}$ dapat diinterpretasi sebagai basalt, batugamping maupun pasir. Lapisan ini diduga merupakan lapisan batugamping terumbu. Batugamping terumbu juga banyak ditemukan sebagai singkapan di permukaan daerah penelitian. Batugamping merupakan batuan sedimen yang dapat menyerap air tetapi sukar untuk menyimpan air karena jenis batuan tersebut cenderung meloloskan air ke lapisan yang ada di bawahnya (Wahyuni dkk., 2018).

\section{Kesimpulan}

Ada pun kesimpulan yang diperoleh dari penelitian ini bahwa pada penampang resistivitas terlihat adanya 3 lapisan yaitu low resistivity $(<6,44 \Omega \mathrm{m})$, medium resistivity $(16,6-285 \Omega \mathrm{m})$ dan high resistivity $285-1892 \Omega \mathrm{m}$. Lapisan ini berturut turut diduga merupakan lapisan lempung-pasir yang memungkinkan mengandung air tanah/ Ground water, lapisan alluvium dan lapisan batugamping terumbu. Penelitian ini dapat menjadi model awal penelitian lebih lanjut dengan menggunakan beberapa lintasan dan diikat dengan penelitian lain yang saling mendukung.

\section{Ucapan Terima Kasih}

Kami mengucapkan terima kasih atas funding support dari Universitas Hasanuddin melalui Hibah Internal Penelitian 2019 Lembaga Penelitian dan Pengabdian Masyarakat. Kami juga berterima kasih kepada Departemen Geofisika, Fakultas Matematika dan Ilmu Pengetahuan Alam, Universitas Hasanuddin (UNHAS) atas dukungannya pada penelitian ini.

\section{Daftar Pustaka}

Bromfield. 2013. Pleistocene reef development in Bulukumba, South Sulawesi. Bulletins of American Paleontology (387) Des. pp 1-60.

Dewi, S., As'ari dan Adey, Tanauma. 2015. Pemetaan Akuifer Air Tanah di Jalan Ringroad, Keluarahan Malendeng dengan Menggunakan Metode Geolistrik Tahanan Jenis. Jurnal Ilmiah Sains, 15(2), 33-37.

Febriana, R.K.N., Minarto, E. dan Tryono, F.X.Y. 2017. Identifikasi Sebaran Aliran Air Bawah Tanah (Groundwater) dengan Metode Vertical Electrical Sounding (VES) Konfigurasi Schlumberger di Wilayah Cepu, Blora Jawa Tengah. Jurnal Sains dan Seni ITS, 6(2), 29-33.

Imran, A. M. 2000. Microfacies and Diagenesis of the Tertiary Selayar Limestone (Walanae Formation), South Sulawesi, Indonesia. 
Dissertation Universitat Erlangen Nuermberg, Jerman. (unpublished).

Imran, A. M., Husein, R., Farida, M., dan Prayudi, A. 2017. Pleistocene reef development in Bulukumba, South Sulawesi. MATEC Web of Conferences. DOI: 10.1051/matecconf/201710104020.

Loke, M.H. 2001. Tutorial 2-D and 3-D Electrical Imaging Surveys.

Reynolds, J.M. 1997. An Introducton to Applied and Environmental Geophysics. John Wiley \& Sons.

Robain H, Bobachev A. 2017. X2IPI Tool box for 2D Electrical Resistivity Tomography and IP measurements User Manual. Available at: http://x2ipi.ru/news/manual.

Sunarya, W., Hasanuddin, Syamsuddin, Maria, Erfan. 2017. Identifikasi Bijih Besi (Fe) Menggunakan Metoda Geolistrik Resistivitas Konfigurasi Wenner - Schlumberger di Kabupaten Luwu. Jurnal Geocelebes, 1(2), 72-81.

Syamsuddin dan Lantu. 2009. Metode Geolistrik dan Geoelektromagnetik. Makassar: Universitas Hasanuddin.

Telford, W.M., Geldart, L.P., Sheriff, E.R. 1990. Applied Geophysics Second Edition. Cambridge: Cambridge University Press.

Utama, W. 2005. Experimental Module Mataram Geophysical Workshop. Lab. Geofisika Fakultas Matematika dan Ilmu Pengetahuan Alam ITS: Surabaya.

Virman, Massinai, M.A., Massinai, M.F.I. 2019. Groundwater Identification at East Sentani Auwena Formation (Tema) Based on Geoelectric. IOP Conf. Ser.: Earth Environ. Sci. 279 012043.

Wahyuni, Jamaluddin, Aswad, S., Armin, L.O. 2018. Investigasi Zona Akuifer Menggunakan Metode Geolistrik Konfigurasi Schlumberger Di Pantai Parangluhu Kecamatan Bontobahari, Kabupaten Bulukumba. Jurnal Geocelebes, 2(2), 78-83. 